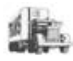

TRANS · NÚM. II · 2007

DOSSIER · 171-175
Los investigadores de la red CEPACC hemos estado trabajando para una Televisión Digital integradora; pero en una sociedad cada vez más digitalizada surgen nuevas necesidades como videojuegos móviles o Internet. Son medios que proporcionan información o facilitan la socialización por lo que la posibilidad de uso debería ser una realidad, pero la preocupación por el cliente discapacitado no parece en general ser algo relevante desde la empresa. Pero sí existen ejemplos de preocupación por las personas con discapacidad, como la Federación Nacional de Ciegos en Estados Unidos (con "The reader» que permite a personas discapacitadas leer cualquier documento), el avatar de la BBC (que imita los gestos y palabra del emisor) o el del proyecto Ulises (que apoya al viajero con discapacidad), entre otros proyectos y retos. Por todo ello, consideramos preciso que en el diseño, a la hora de implantar nuevos modelos, servicios y herramientas para el usuario/consumidor, se tenga en consideración que existen diferentes tipos de necesidades.

PALABRAS CLAVE: Discapacidad. Medios de comunicación. Nuevas Tecnologias. Proyecto ULISES. Lengua de Signos/Señas. Video Games. Televisión Digital.

\title{
Nuevos retos de la accesibilidad en los medios
}

Alvaro Pérez-Ugena, Rafael Linares \& Ricardo VizCAINO-LAORGa

Universidad Rey Juan Carlos (Madrid)
The CEPACC group's researchers have been working for an integrating Digital Television, but new needs have apeared in a society that becomes more and more digitilized, like videogames, cellphones or internet. These are means that provide information or make socialization easier so their posibility of use should be a reality, but focusing in a handicapped client does not seem to be important. But there are examples of the concern about the handicapped like the National Federation of the Blind in the United States with "the reader" which alows handicapped people to read any document, the BBC avatar that imitates gestures and words of the speaker, the Ulises project that supports the handicapped traveller, and a lot more challenges. Because of all this, we think that different kinds of needs must be taken into account in the designing proces when we want to implant new models, services and tools for the user/consumer.

KEY WORDS: Handicapped. Mass Communication Media. New Technologies. ULISES Project. Sign Language. Videojuegos. Digital Terrestrial Television. 
El título del artículo que escribimos pretende despertar la curiosidad del estudioso sobre las posibilidades de la accesibilidad en los medios audiovisuales. E1 reto que hace ya cerca de tres años afrontamos los investigadores de la en aquellos años inexistente red de Ciencia y Empresa por la Accesibilidad de la Comunicación (CEPACC) era hacer de la Televisión un medio accesible. Fruto de las primeras investigaciones vieron la luz diversas publicaciones monográficas (TV digital e integración: $\dot{\dot{\zeta} T e l e v i-}$ sión para todos? así como Sociedad TV e integración, $\dot{i}$ Estamos Todos?), se organizaron seminarios nacionales como AMADIS e internacionales como MEDia FOR ALL ${ }^{\mathrm{I}}$, se creó el Centro Español de Subtitulado y Audiodescripción (CEsyA) y la sociedad tomó conciencia entre otras cosas del hecho de que la Televisión Digital debía ser un proyecto que ya desde sus inicios contara e incluyera a todas las personas, independientemente de si contaban o carecían de algún tipo de discapacidad. El fruto es la Televisión Digital integradora que todos esperamos tener.

Todo lo anterior es positivo y por ello ilusionante; especialmente cuando el legislador da cobertura a gran parte de las demandas planteadas y sitúa a España en el lugar que le corresponde dentro del marco europeo. Sin embargo, ya vislumbramos las nuevas necesidades, fruto del nuevo rumbo que toma la sociedad, cada vez más digitalizada, cada vez más tecnológicamente dependiente.

Por una lado encontramos, entre la población más joven, y por ello más sensible a los problemas de integración la necesidad de participar de las actividades propias de su edad: los videojuegos. ¿Cuántos videojuegos accesibles existen? ¿Cuántas películas o DVDs son accesibles?2

Videojuegos, televisión, móviles o Internet

I http://www.fti.uab.es/transmedia son medios y soportes que en una sociedad avanzada - económicamente hablando- se convierten en una necesidad, unas veces profesional pero fundamentalmente social y hasta vital. Algunos proporcionan información o facilitan la socialización, educan o entretienen. En el caso de los videojuegos «los jugadores discapacitados son consumidores, y la posibilidad de jugar es una cuestión de la propia calidad de vida. Las personas juegan para divertirse, no para sentirse frustrados» ${ }^{3}$. Y no sólo eso: los videojuegos pueden ser fuentes educativas y hasta terapéuticas, y por ello la posibilidad de uso debería ser, de hecho, una realidad.

A diferencia de lo que se pueda pensar, el interés por los videojuegos no es una cuestión de edad o sexo ${ }^{4}$ y mucho menos debería ser un problema de discapacidad. Así lo entiende la International Game Developers Association y su grupo de trabajo dedicado a los videojuegos ${ }^{5}$, que

2 Luk internacional lanza por primera vez en España un DVD de animación infantil accesible para todos los niños. El DvD de «Doraemon en el mágico mundo de las aves», realizado por la compañía de authoring Voilà DvD Art Studio, añade a sus cinco navegaciones de siempre la opción de audionavegación y de audiodescripción en castellano, lo que permite a las personas con discapacidad visual poder disfrutar de la película. El DvD se completa con subtítulos adaptados para sordos, también en castellano. La intención de Luk Internacional es ser accesible a todos los usuarios, por ello, esta opción se incluirá en los futuros lanzamientos de la compañía. Luk Internacional ha contado con la colaboración de Voilà DvD Art Studio, creadores del innovador sistema de audio-navegación, y con la aprobación de la ONCE.

3 Bierre, Chetwynd, Ellis, Hinn, Ludi y Westin: Game not over: Accessibility signes in video games. Games Accessibility Special Interest Group. International Game Developers Association. California, p. 2, 2005.

4 Por edades la distribución es relativamente homogénea: el 38\% de los jugadores tienen menos de i8 años, el $42 \%$ se incluyen en la franja entre los I8 y los 34 años y el $20 \%$ se encuentra por encima de esta edad. Por sexos sí existe una dominancia masculina, con un $67 \%$. Según el Estudio de Hábitos y Usos de los Videojuegos de aDeSe, p. 8. Febrero de 2005. GfK Group. 
promueve la consideración de los discapacitados como un cliente más. Pero si a partir de 1998 muchas organizaciones hicieron suya la idea de hacer sus sitios/webs accesibles ${ }^{6}$ y aún hoy (casi Io años después) la accesibilidad en Internet dista de ser una realidad, en el caso de los videojuegos el problema es aún más complejo al de otros medios audiovisuales. Ello se debe a que puede incluir problemas tanto para discapacitados visuales, auditivos, motrices y cognitivos. Pero el problema mismo es la solución para más de tres millones de personas sólo en España, lo que se traduce en más de 600.000 clientes potenciales 7 para la industria del videojuego.

Pero la preocupación en los videojuegos no parece centrarse hoy en la accesibilidad, sino en cuestiones morales y educativas. Desde marzo de $2003^{8}$ viene actuando el Pan European Game Information (PEGI), que ofrece información estandarizada sobre la edad recomendada y perfil (juego de azar) o contenido del videojuego (violencia, terror, sexo, drogas, lenguaje soez o discriminación) y se aplica actualmente en i6 países (entre ellos España). Sin embargo, la preocupación por el cliente discapacitado no parece ser algo relevante para una industria que en España factura más de 800 millones de

\footnotetext{
5 Se trata del Games Accessibility Special Interest Group.

6 En la Workforce Investment Act de I998, la cuestión de la accesibilidad se convierte en Estados Unidos en un problema de interés nacional por medio del artículo 508 (a.I) de esta ley, que plantea la necesidad del acceso a la información electrónica.

7 Las cifras de la encuesta nacional más reciente (Encuesta de Discapacidades, Deficiencias y Estado de Salud 1999. Instituto Nacional de Estadística) son de 3.528.220 discapacitados. Si se restringe el número a las personas entre 6 y 44 años, incluiría a 668.038 individuos.

El proyecto PEGI se inició en mayo de 20oI, según información de la Asociación Española de Distribuidores y Editores de Software de Entretenimiento (aDeSe). En www.adese.es.
}

euros $^{9}$ e involucra a ocho millones y medio de personas ${ }^{\text {Io }}$. Es muy probable que, como en otros aspectos de la accesibilidad, la tecnología exista, pero no su aplicación. Un estudio reciente sobre accesibilidad en los videojuegos ${ }^{\mathrm{II}}$ indica que $\mathrm{o}$ bien algunas de las tecnologías existentes para discapacitados no se aplican convenientemente a los videojuegos, o bien los videojuegos no se adaptan a las tecnologías de los discapacitados. Así, los controladores alternativos ${ }^{12}$ (que dirigen las acciones a través de los movimientos de la cabeza, de los ojos o del cuerpo) pueden ser rápidos pero imprecisos o muy precisos pero lentos. Pequeñas modificaciones en el software (como la posibilidad de alterar la velocidad del juego o el grado de precisión del mismo) podrían solucionar para muchas personas el problema de accesibilidad. Y es probable que en buena parte sea una cuestión de actitud, una falta de preocupación por este colectivo, pues técnicamente es factible. De hecho, los videojuegos permiten aplicar diferentes grados de dificultad; el problema es que estos niveles están pensados para usuarios sin handicaps, y pueden no ser suficientes para personas con, por ejemplo, determinadas discapacidades motrices. Bastaría con incluir otros niveles mucho más lentos, niveles que a un jugador sin «facultades plenas» podrían aburrir, pero que cumpliría las expectativas de otro público.

La inversión en hacer accesible un video-

9 En 2005 fueron 863 millones de euros, por delante de otros sectores de entretenimiento como el cine, vídeo o la música grabada, según la aDeSe (Dossier de Prensa, Galardones aDeSe 2006. Julio 2006. Disponible en: http://www.adese.es/pdf/Dossier_de_prensa_Galardones_aDeSe_20o6.pdf).

Io Según el Estudio de Hábitos y Usos de los Videojuegos de aDeSe, p. 7. Febrero de 2005. GfK Group.

II Realizado entre 2003 y 2004 por el Game Accessibility Special Interest Group, de la Internacional Game Developers Association.

I2 Alternative Pointing Devices. 
juego no parece ser determinante. «Half Life $2^{13}$ » (cuyo lanzamiento se realizó en España a finales de 2004) incluyó las sugerencias de jugadores sordos sobre «Half Life» (1998) acerca de la necesidad de introducir subtítulos para $\operatorname{sordos}^{\mathrm{I}}$. Otros juegos, como «Terraformers», emplean múltiples métodos para orientar al jugador, como sonidos para indicar dirección, proximidad, tipo de objetos ${ }^{15} \ldots$ o diseños ${ }_{3} \mathrm{D}$ de alto contraste para personas con problemas de visión.

Es posible que, al menos en parte, se dé un paso adelante en la accesibilidad con la aparición de Wii (Nintendo, diciembre de 2006), un nuevo concepto de interface que hace desaparecer el teclado o el joystick tradicional y lo sustituye por un aparato (similar a un mando de televisor) que se adapta a cada juego, y permite "transformarse» en un palo de golf, un bate de béisbol o una batuta para dirigir una orquesta ${ }^{16}$.

Pero la industria se encuentra volcada en otros muchos ámbitos. Tanto en Estados Unidos ${ }^{17}$ como en Europa la preocupación en dotar de servicios a las personas con discapacidad ${ }^{18}$ puede ejemplificarse del siguiente modo:

- La Federación Nacional de Ciegos de Estados Unidos dispone de 'The reader', un dispositivo portátil que permitirá a las personas ciegas

I3 Se trata de un videojuego de enorme éxito en todo el mundo. En España aDeSe la premió en 2005 con un disco de oro por superar las 40.000 copias vendidas en nuestro país y se hizo con 9 premios en la Interactive Achievement Awards (los Oscars de los videojuegos), según recoge el Anuario 2005 de aDeSe. Disponible en http://www.adese.es/pdf/anuario-memoria-2005.pdf.

I4 No se trata de meros subtítulos de idiomas, sino de subtítulos especiales para sordos (en inglés close captions).

is Transformers fue el ganador a la «Innovación en Audio» en el Independent Games Festival de 2003. Información disponible en http://www.igf.com/ 2003 finalistswinners.html

I6 En http://ms.nintendo-europe.com/wii. y con discapacidad visual leer cualquier tipo de documento, aunque no esté en braille. Se trata de una cámara digital que filma el texto y después lo convierte en audio, mediante un miniordenador que lleva incorporado. El dispositivo tiene una capacidad de reconocimiento de caracteres tan precisa que puede traducir cualquier tipo de textos, desde tarjetas de crédito y billetes de avión, a facturas y menús de restaurantes. El aparato tiene un tamaño ligeramente superior al de un teléfono móvil, y su usuario puede escuchar la transcripción en audio con auriculares y ajustar la velocidad de reproducción de los mismos.

- Una cadena de televisión hispana, pese a no contar con la obligación legal de hacerlo, inició un servicio especial de narración de escenas para personas con discapacidades visuales en Estados Unidos y Puerto Rico que llegará a unos I4 millones de espectadores por cable y satélite. El nuevo servicio se suma a los subtítulos ya disponibles para personas con falta de audición de la cadena educativa HITN-TV y está financiado por el Departamento de Educación de Estados Unidos. El servicio permite que personas ciegas escuchen la narración de escenas que suceden entre dos diálogos, donde se intercala la descripción.

- La realidad virtual también va incrementando su nivel de prestaciones; el avatar conocido como Anna Nova, la presentadora de televisión

I7 En el mundo hay 37 millones de personas ciegas y otros I24 sufren problemas de visión. El 80\% de estos casos son curables a través de técnicas y tratamientos comunes en Occidente, pero el 90\% de los pacientes no tiene acceso a esta asistencia. Proyectos como Cybercampus Ojos del Mundo cuyo objetivo es formar a médicos de los territorios más pobres del planeta en especialidades oftalmológicas a través de tecnologías de la información y la comunicación, como la videoconferencia e Internet constituye toda una iniciativa desarrollada sin especial apoyo de la industria. Internet, contra la ceguera EL PAís Sociedad - 25-09-2006.

I8 Según la Oficina del Censo, de las 53,9 millones de personas con discapacidades que viven en Estados Unidos, 8,2 millones son de origen hispano. 
de la $\mathrm{BBC}$ ha retornado a la actividad gracias a la entrada del operador de telefonía móvil, Orange, de France Telecom, que ha decidido utilizar esta tecnología con el objeto de dotar de mayores servicios a sus abonados. Pero las innovaciones llegan de la mano de la siempre innovadora industria japonesa — que junto a la operadora NTT Docomo- que permite que el avatar imite los gestos y las palabras que quiera realizar el emisor en ese momento. De aquí al éxito de proyectos como la iniciativa Ulises - proyecto para la creación de un avatar de apoyo al viajero con discapacidad a través de la utilización de la lengua de signos-, al que únicamente falta el apoyo institucional ${ }^{19}$. El desarrollo tecnológico en la creación de imágenes simuladas en tiempo real y, sobre todo, los avances en la generación de voz mecánica, han logrado consagrar una nueva generación de personajes simulados que están consiguiendo sus primeros y modestos éxitos en escenario multimedia de la telefonía celular de tercera generación.

- El sistema MoPix para cines (modelo de subtitulación patentado por Rear Window que oferta subtítulos optativos al tiempo que realiza audiodescripciones para las personas ciegas) permite que las personas con discapacidad obtengan descripciones de los principales elementos de la película sin distraer a los demás espectadores de la sala ${ }^{20}$ pasamos a proyectos más personalizados, en lo que pretende ser la implantación de dicha tecnología en gafas personalizadas para el usuario final.

Las referencias a las que hemos hecho mención

19 Mientras se redactaba el presente artículo, el proyecto ulises, Utilización Lógica e Integrada del Sistema Europeo de Signos/Señas liderado por la Universidad Rey Juan Carlos y, en la que participan la UAB, la UCM, la UPM junto con Barcelona Media, empresa líder del sector de tecnología multimedia, ha recibido una ayuda del Ministerio de Trabajo y Asuntos Sociales de 78.0oo euros para la puesta en marcha del proyecto. dejan en el tintero gran cantidad de proyectos y de retos para investigadores, la industria y las asociaciones representantes de la discapacidad. Algunos pueden parecer ciencia ficción —al menos para los menos tecnólogos- como cuando se analiza la utilización de las ondas alfa para el encendido y apagado de ordenadores, televisiones o cualquier otro aparato, pero la evolución tecnológica no deja de sorprendernos. Por ello, desde la perspectiva descrita únicamente consideramos precisa una actuación: que en el diseño, a la hora de desarrollar e implantar nuevos modelos, nuevos servicios y nuevas herramientas para el usuario/consumidor, se tenga en consideración el hecho de que existen diferentes tipos de necesidades.

RECIBIDO EN DICIEMBRE 2006

ACEPTADO EN ENERO 2007

20 Creado en 1992, hoy el Centro de captación lleva a cabo más de Io.00o horas de programación anual en diversos ámbitos; televisión, vídeos, vídeos musicales, películas. Se utilizan los paneles de acrílico transparentes unidos a sus asientos para reflejar los subtítulos de modo que aparezcan sobrepuestos en o debajo de la pantalla de la película. Los subtítulos no están en la película en sí misma. Los subtítulos están en un disquete o un CD en los que entran en juego la sincronización con la película. Los subtítulos son visibles (vía un reflector) solamente a esas personas que elijan verlos. Los subtítulos están disponibles durante presentaciones a través de una programación regular. No hay coste adicional para ver los subtítulos. Asimismo las descripciones se sincronizan a la película, consiguiéndose con ello una integración total de las personas con algún tipo de discapacidad y contribuyéndose al diseño para todos. Las descripciones se narran y se registran sobre una cinta magnética para audio o un disco que se puedan sincronizar a la película mientras que se proyecta. Los cines convencionales utilizan el sistema audio digital de DTs para jugar las descripciones de la película. El sistema de DTs proporciona el audio digital de varios canales en el CD-ROM. La narración descriptiva reside en un CD este se aplica junto a los otros discos en sistema de DTs. Una cabeza especial del lector unida al proyector de la película lee una pista del time-code impresa en la película y señala al play del DTs que debe aplicar el audio en sincronía a la película. El play de DTs envía las descripciones a un infrarrojo o al emisor de FM. Los costes varían de cine dependiendo de factores como tamaño y el equipo existente. 